\title{
A educação em saúde em escolas públicas da zona rural: relato de experiência
}

\author{
Ana Beatriz Clemente Gonçalves ${ }^{1}$ \\ Flávia Mesquita Soares ${ }^{2}$ \\ Pamella Donadoni Coelho ${ }^{3}$ \\ Rafael de Oliveira Alvim ${ }^{4}$ \\ Carlos Alberto Mourão Júnior ${ }^{5}$ \\ Camila Maciel de Oliveira ${ }^{6}$
}

Resumo: O objetivo deste estudo foi descrever uma ação de educação em saúde em escolas da zona rural e comparar seu aproveitamento com a experiência prévia em áreas urbanas. Métodos: foi apresentada uma peça teatral infantil, durante dois dias do mês de março de 2016, falando sobre o processo de envelhecimento e discutindo o cuidado com idosos. As crianças tinham de 4 a 10 anos e pertenciam a três escolas da zona rural. Os resultados evidenciaram que as crianças participaram ativamente e demonstraram ter absorvido as ideias que estavam sendo transmitidas. Conclui-se apesar das dificuldades apresentadas na zona rural, o aproveitamento foi similar ao obtido em áreas urbanas.

Palavras chave: Educação em Saúde; Educação Infantil; Educação no Campo; Intervenções Comunitárias

\begin{abstract}
The aim of this study was to describe a health education action in rural schools and compare its results with previous experience in urban areas. Methods: a children's theater play was performed during two days of March 2016, talking about the aging process and discussing elderly care. The children were 4 to 10 years old and belonged to three rural schools. The results show that children participated actively and shown to have absorbed the ideas that were being transmitted. We conclude that despite the difficulties presented in the countryside, the improvement was similar to that obtained in urban areas.
\end{abstract}

Keywords: Health Education; Early Childhood Education; Education in the Countryside; Community interventions.

\footnotetext{
${ }^{1}$ Acadêmica de medicina, UNIPAC, anabeatriz.medjf@gmail.com

${ }^{2}$ Acadêmica de medicina, UNIPAC, flavymesquita@ hotmail.com

3 Acadêmica de nutrição, UFJF, pampamvrb@gmail.com

${ }^{4}$ Doutor em Ciências, UFES, alvimfaefid@ig.com.br

${ }^{5}$ Doutor em Ciências, UFJF. camouraojr@gmail.com

${ }^{6}$ Doutora em Ciências, UFPR, camilamacieloliveira@gmail.com
} 


\section{Introdução}

A promoção da saúde visa buscar a melhoria da qualidade de vida da população. Seu objetivo é produzir a gestão compartilhada entre usuários, movimentos sociais, trabalhadores do setor sanitário e de outros setores, produzindo autonomia e corresponsabilidade.

Nos últimos 25 anos, a promoção da saúde mostrou-se promissora para enfrentar os múltiplos problemas que afetam a sociedade, como aponta Buss (2000). Esse autor, partindo de uma concepção ampla do processo saúde-doença e de seus determinantes, propõe a articulação de saberes técnicos e populares, e a mobilização de recursos institucionais e comunitários, públicos e privados, para seu enfrentamento e resolução.

Uma das estratégias mais importantes na promoção da saúde é a educação em saúde. Nesse sentido, de acordo com Fernandes et al. (2005), a escola pode ser vista como um ambiente propício para a aplicação de programas de educação em saúde, pois a mesma está inserida em todas as dimensões do aprendizado.

A promoção da saúde no âmbito escolar parte de uma visão integral e multidisciplinar do ser humano, que considera as pessoas em seu contexto familiar, comunitário, social e ambiental.

As escolas promotoras de saúde facilitam a transmissão de conhecimentos e habilidades que promovem o autocuidado com a saúde, além da prevenção de comportamentos nocivos. A promoção da saúde nas escolas contribui para o desenvolvimento de atitudes que favorecem a saúde e incentivam a formação de jovens dotados de espírito crítico e capazes de refletir sobre os diferentes modos de vida necessários para o desenvolvimento humano.

Dados do Instituto Nacional de Estudos e Pesquisas Educacionais Anísio Teixeira (Ministério da Educação, 2007), apontam que as escolas públicas brasileiras são responsáveis pela educação de 45 milhões de alunos, sendo que 35,8 milhões de alunos frequentam o ensino fundamental. Dentre os alunos do ensino fundamental, 32,4 milhões (90,5\%) estudam em escolas públicas e 3,4 milhões (9,5\%) em escolas particulares, sendo que há apenas 76,2 mil escolas rurais para atender 8,4 milhões de pessoas em idade escolar que vivem no campo.

É sabido que a maioria dos estudantes da zona rural não consegue concluir sequer o ensino médio. Alguns entraves dificultam o aprendizado dos alunos do campo, tais como: Revista Extensão em Foco, nº 15, Jan/ Jul, p. 86 - 94, 2018. 
transporte que muitas vezes não chega a alguns povoados distantes, estradas que ficam em péssimas condições no período das chuvas, classes superlotadas, classes multisseriadas e insuficiência de materiais didáticos.

São raros os estudos na literatura que avaliam intervenções comunitárias em escolas da zona rural, por conta das dificuldades e barreiras para o acesso às escolas dessas regiões. $\mathrm{O}$ presente estudo tem por objetivo descrever a percepção pessoal e subjetiva dos autores acerca de uma atividade extensionista de educação em saúde, realizada com escolares, visando a promoção da saúde, ocorrida no início de março de 2016, em escolas da zona rural do município de Baependi-MG. Além disso, faremos algumas comparações das intervenções realizadas com intervenções passadas conduzidas em áreas urbanas.

\section{Metodologia}

Existe há mais de 10 anos, no município de Baependi-MG, o projeto Corações de Baependi, um estudo genético de doenças cardiovasculares, desenvolvido pelo Instituto do Coração (InCor) e Faculdade de Medicina da Universidade de São Paulo (FMUSP). Porém, partindo da necessidade de uma maior interação com a comunidade para a promoção da saúde e mudanças dos hábitos de vida, surgiu um projeto subsidiário, denominado "Coraçõezinhos de Baependi”.

O projeto "Coraçõezinhos de Baependi, composto por docentes médicos da Universidade Federal do Paraná (UFPR), Universidade Federal de Juiz de Fora (UFJF) e por acadêmicos de medicina da Universidade Presidente Antônio Carlos de Juiz de Fora, tem por objetivo promover ações educativas em saúde, de forma lúdica, para crianças das redes públicas e privadas do município de Baependi-MG.

Em virtude da ausência de ações voltadas para a promoção da saúde em áreas de difícil acesso, o projeto Coraçõezinhos de Baependi elaborou uma intervenção comunitária especialmente voltada para escolares da zona rural do município. O tema abordado para a atividade lúdica foi o envelhecer e o cuidado com o idoso, visando à conscientização e o respeito aos idosos, uma vez que o aumento da população idosa e a inversão da pirâmide demográfica constituem importante tema de debate em diferentes setores da sociedade contemporânea.

Revista Extensão em Foco, nº 15, Jan/ Jul, p. 86 - 94, 2018. 
Em parceria com a Prefeitura Municipal de Baependi, foi agendada previamente para os dias 1 e 2 de março de 2016, as visitas às três escolas da zona rural, com a autorização da direção das mesmas. Foi elaborada e entregue uma carta de autorização que descrevia o tema, o conteúdo e o objetivo da intervenção em questão. As autorizações foram devidamente assinadas e o presente projeto foi cadastrado na Pró-Reitoria de Extensão da UFJF sob o ${ }^{\circ}$ 7129.3.9818.15042015.

A base da intervenção foi a peça de fantoches intitulada "Lulu, a taturana que não queria envelhecer" de autoria dos docentes do projeto. A história é composta por um narrador e dois personagens e retrata o diálogo entre uma criança (Maria) e uma taturana (Lulu) que se recusava a envelhecer, mostrando as dificuldades próprias do envelhecimento, tais como: baixa acuidade visual, surdez, dificuldades motoras, utilização de órteses, o aparecimento de doenças crônicas, além da preocupação do idoso com sua família.

A peça demonstra a vida de uma taturana idosa que era muito estressada e impaciente. A taturana apresentava movimentos lentos, dificuldade de locomoção, usava prótese auditiva, tinha catarata, usava medicamentos para a memória e só gostava de arrumar casa e fazer comida para os netos. A taturana encontra a menina Maria e começa a contar para ela sobre sua vida e relatar suas dificuldades. Maria consola a taturana dizendo que ela não deve se entristecer pelo seu estado, pois todos irão envelhecer, já que o envelhecer é uma etapa natural da vida.

A confecção de um dos personagens (a taturana) foi feita com uma caixa de ovos reutilizada. Os objetos citados na peça como relógio, vassouras e alimentos foram elaborados com diferentes cores de Etileno Acetato de Vinila (conhecido com EVA), e amarrados a hastes de madeira. Quanto à montagem do cenário, utilizamos uma cortina de aproximadamente dois metros quadrados, especialmente produzida para a apresentação de teatro de fantoches e amarrada com barbantes no espaço cedido pela instituição. Também utilizamos dispositivos luminosos como brinquedos de neon e balões. Foi elaborada uma atividade para colorir, relacionada ao tema, que foi entregue para cada criança no final das apresentações.

O início da intervenção foi realizado após a confirmação do número total de alunos presentes no respectivo dia, em cada instituição. Antes da peça, houve a apresentação da equipe do Projeto Coraçõezinhos de Baependi por duas acadêmicas de medicina abordando a questão: a promoção da saúde, a consciência e o respeito aos idosos. Cada intervenção durou cerca de Revista Extensão em Foco, nº 15, Jan/ Jul, p. 86 - 94, 2018. 
30 minutos, e o número total de alunos atendidos pelo projeto foi de 109 crianças. As crianças tinham de 4 a 10 anos e cursavam desde a pré-escola até o $5^{\circ}$ ano do ensino fundamental.

\section{Resultados}

Passaremos a expor nossas percepções sobre as intervenções realizadas, descrever as dificuldades encontradas para a realização das mesmas, e comparar alguns aspectos das intervenções em áreas rurais descritas nesse artigo com intervenções realizadas anteriormente em áreas urbanas.

Agendadas data e horário para as visitas nas escolas, a equipe do projeto contou com o apoio de um veículo da prefeitura para o transporte às escolas do campo, já que os ônibus intermunicipais para as algumas regiões rurais são escassos. O tempo gasto da saída do centro da cidade à chegada em algumas zonas rurais foi de aproximadamente 2 horas, uma vez que o caminho muitas vezes exigia do condutor atenção e paciência, já que grande parte das estradas era de terra, não asfaltada e, devido às chuvas locais, encontravam-se escorregadias e cheias de obstáculos como buracos ou grandes poças de água, além de muita lama.

Na chegada às escolas, a equipe pôde se deparar com o carinho e atenção da direção, semelhante ao que ocorreu nas escolas da rede urbana. Durante a apresentação (Figura 1) da equipe do Projeto Coraçõezinhos de Baependi, ocorreu um breve diálogo com as crianças através de um bate-papo leve e divertido que abordava o tema em questão. As crianças se mostraram receptivas e participativas, relatando como elas se relacionavam com os avós em suas casas.

Figura 1 - Início da intervenção e apresentação do projeto. Fonte: Arquivos do Projeto Coraçõezinhos de Baependi

Revista Extensão em Foco, nº 15, Jan/ Jul, p. 86 - 94, 2018. 


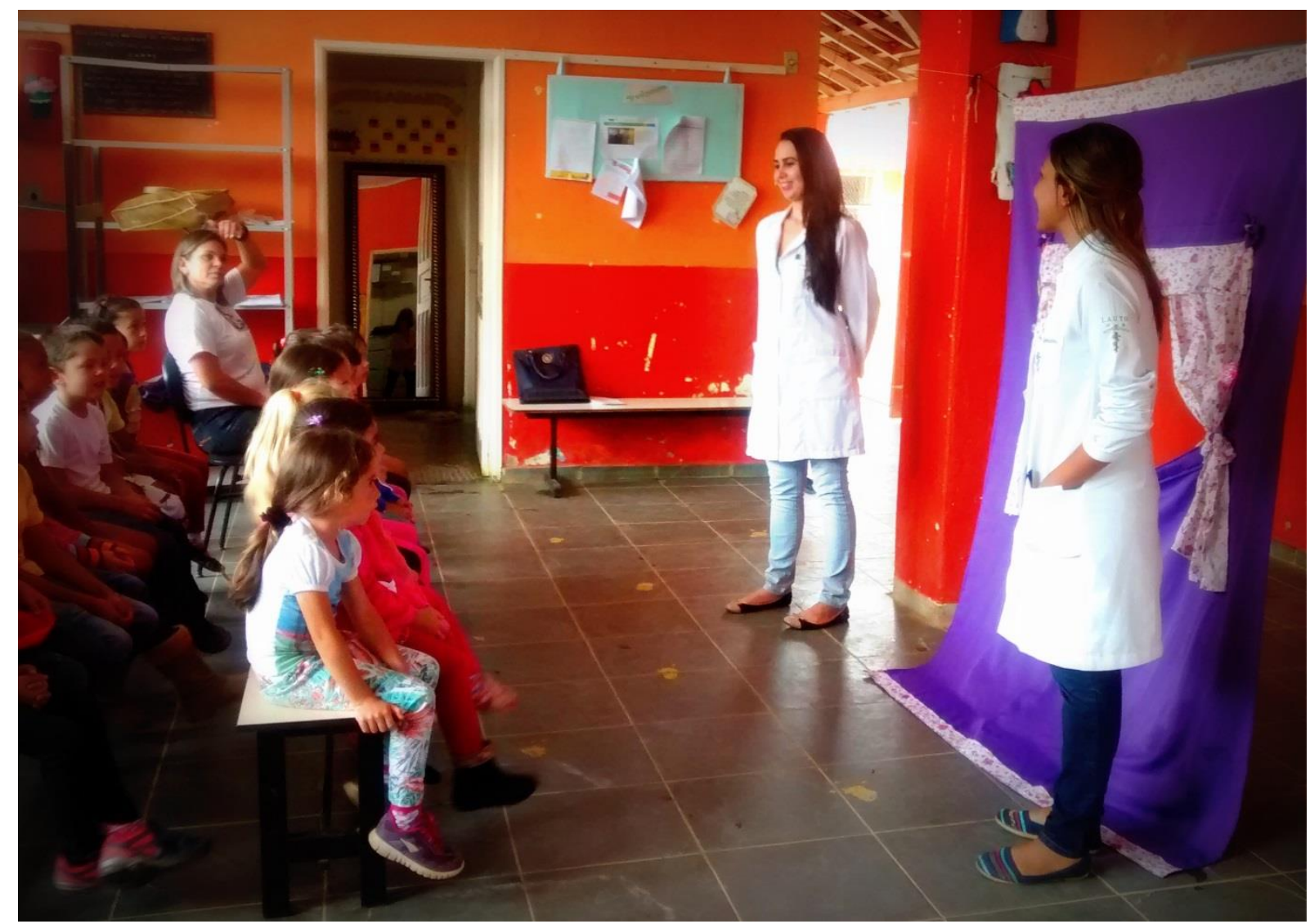

Fonte: Dados dos pesquisadores (2017)

A intervenção correu de forma tranquila e satisfatória, a equipe pôde abordar questões acerca do envelhecimento de forma dinâmica e com a participação dos alunos. À semelhança com os alunos de instituições de ensino urbanas, muitos alunos mostraram-se conscientes acerca do envelhecer, do cuidado com o idoso, bem como descreveram ações voltadas para melhorias e promoção da saúde. Muitos questionaram sobre as principais doenças que aparecem com o envelhecer e tiveram suas dúvidas sanadas pela equipe do projeto, que foi devidamente treinada. Muitos relataram promover a saúde quando dão lugar a um idoso num ônibus lotado ou ajudam seus avôs nas tarefas diárias como manter a casa arrumada, evitando objetos espalhados pela casa para evitar a queda do idoso. O encerramento da ação ocorreu após entrega de atividades para colorir, que retrataram o tema abordado.

\section{Discussão}

Revista Extensão em Foco, nº 15, Jan/ Jul, p. 86 - 94, 2018. 
Embora o acesso ao ensino seja dado como universalizado em todo o Brasil, a persistência das desigualdades educacionais entre as zonas rural e urbana continua presente. Quando comparamos o número de alunos das zonas rurais com o número de alunos da zona urbana, percebemos que o número de alunos matriculados no campo é bem menor do que na cidade. Isso pôde ser visto na intervenção que contou com uma média de 109 alunos do campo, enquanto que tais ações nas instituições urbanas contaram com a presença de 410 crianças, em apenas 3 das muitas redes de ensino, com alunos das mesmas séries e idades. O reduzido número de escolas no campo associado às dificuldades de transporte, contribui para essa divergência.

O acesso a muitas instituições rurais foi dificultado pela estrada, que em sua maior parte era de terra, e pelas chuvas que caíam no período da intervenção, reforçando uma das dificuldades dos alunos da zona rural em ir às escolas. As estradas encontravam-se escorregadias, cheias de lama, poças de água, além da presença constante de animais como vacas ou cavalos, no caminho, o que exigiu do condutor mais atenção e paciência. Dessa forma, a média de tempo total da ação, contando o deslocamento da cidade ao campo, a duração da intervenção e o retorno do campo para a cidade, foi de aproximadamente 4 a 5 horas.

Quanto à infraestrutura, embora a maioria das escolas rurais do país estejam em precárias condições de ensino, a equipe do projeto, observou que as escolas participantes da ação, pertencentes à zona rural do município de Baependi-MG que foram: Escola Estadual Joaquim Alvarenga Maciel (conhecida como Escola do Povoado de Piracicaba), Pré-Escola Municipal São Pedro (conhecida como Escola do Povoado de São Pedro) e Escola Estadual Vargem da Lage (apelidada de Escola das Vargens), se encontravam em boas condições de salas, espaços e auditórios para as apresentações, não existindo muita divergência se compararmos os espaços das escolas rurais aos das urbanas. Em Baependi-MG, as escolas da zona rural que receberam as intervenções comunitárias para a promoção da saúde, apresentam infraestrutura e tamanhos, relativamente semelhantes às escolas da cidade.

Quanto a recepção da direção, dos alunos e professores, o Projeto Coraçõezinhos de Baependi, mostrou-se satisfeito com tamanho carinho e atenção, desde da oferta de ajuda para a montagem do cenário da intervenção por parte da direção e de alguns funcionários da

Revista Extensão em Foco, nº 15, Jan/ Jul, p. 86 - 94, 2018. 
instituição ao interesse das crianças para com o tema, através de dúvidas, relatos e disposição em aprender.

\section{CONSIDERAÇÕES FINAIS}

A intervenção realizada, descrita no presente relato, mostrou-se positiva e enriquecedora para toda a equipe do projeto. Como nas intervenções realizadas em escolas urbanas, a equipe foi carinhosamente recebida pelas instituições de ensino da zona rural. Muitas crianças mostraram-se atentas e dispostas a receber as informações prestadas. Não observamos diferença no conhecimento prévio sobre saúde entre alunos das instituições rurais e alunos da cidade. Apesar das dificuldades e barreiras para o acesso às escolas da zona rural, concluímos que ações educativas sobre a saúde neste meio podem contribuir para o desenvolvimento local e servir como propostas de novas intervenções comunitárias para crianças e jovens do campo.

Com efeito, segundo o educador, pedagogo e filósofo brasileiro Paulo Freire (2002): “Onde quer que haja mulheres e homens, há sempre o que fazer, há sempre o que ensinar, há sempre o que aprender".

\section{Agradecimento}

Os autores agradecem os recursos disponibilizados pelo Prefeitura Municipal de Baependi-MG através do transporte às zonas rurais do município e da disposição para com o projeto.

\section{Referências Bibliográficas}

BUSS, Paulo Marchiori. Promoção da saúde e qualidade de vida. Ciência \& Saúde Coletiva, v. 5, n. 1, p. 163-177, 2000.

Revista Extensão em Foco, nº 15, Jan/ Jul, p. 86 - 94, 2018. 
FERNANDES, Marcos Henriques; ROCHA, Vera Maria; DE SOUZA, Djanira Brasilino. A concepção sobre saúde do escolar entre professores do ensino fundamental ( $1^{\mathrm{a}}$ a $4^{\mathrm{a}}$ séries). História, Ciências, Saúde - Manguinhos, v. 12, n. 2, p. 283-291, maio-ago. 2005.

FREIRE, Paulo. Pedagogia da autonomia: saberes necessários à prática educativa. 21 ed. São Paulo: Paz e Terra, 2002.

MINISTÉRIO DA EDUCAÇÃO. Instituto Nacional de Estudos e Pesquisas Educacionais Anísio Teixeira-INEP. Panorama da educação no campo. Brasília, 2007.

Revista Extensão em Foco, nº 15, Jan/ Jul, p. 86 - 94, 2018. 